\title{
Potential production of 2-phenylethanol and 2-phenylethylacetate by non-Saccharomyces yeasts from Agave durangensis
}

\author{
Pablo Jaciel Adame-Soto ${ }^{1}$ Elva Teresa Aréchiga-Carvajal ${ }^{2}$ - Mercedes G López ${ }^{3}$. Silvia Marina González-Herrera ${ }^{1}$. \\ Martha Rocio Moreno-Jiménez ${ }^{1} \cdot$ Norma Urtiz-Estrada $^{4} \cdot$ Olga Miriam Rutiaga-Quiñones $^{1}$
}

Received: 14 February 2019 / Accepted: 29 May 2019 / Published online: 17 June 2019

(C) Università degli studi di Milano 2019

\begin{abstract}
Introduction The participation of non-Saccharomyces yeasts in fermentation processes is of great importance due to their participation in the formation of esters and superior alcohols, which confer characteristic aromas to beverages such as wine and mescal.

The aim The aim of this study was identify and evaluate the potential aroma production of yeast native of Agave fermentation by the mescal production in Durango, Mexico. Isolated yeasts were molecularly identified by 5.8 s ribosomal gene; the potential production of aromas was carried out in fermentations with the addition of L-phenylalanine and evaluated after $24 \mathrm{~h}$ of fermentation. Extraction and quantification of aromatic compounds by headspace solid-phase micro-extraction (HS-SPME) and gas chromatograph mass spectrometry (GC-MS).

Results The isolated non-Saccharomyces yeasts could be classified into six different genera Saccharomyces cerevisiae, Clavispora lusitaniae, Torulaspora delbrueckii, Kluyveromyces dobzhanskii, Kluyveromyces marxianus, and Kluyveromyces sp. All probed strains presented a potential aroma production (ethyl acetate, isoamyl acetate, isoamyl alcohol, benzaldehyde, 2-phenylethyl butyrate, and phenylethyl propionate), particularly 2-phenylethanol and 2-phenylethylacetate; the levels found in the Kluyveromyces marxianus ITD0211 yeast have the highest 2-phenylethylacetate production at $203 \mathrm{mg} / \mathrm{L}$ and Kluyveromyces marxianus ITD0090 with a production of 2-phenylethanol at $1024 \mathrm{mg} / \mathrm{L}$.

Conclusion Non-Saccharomyces yeasts were isolated from the mescal fermentation in Durango; the Kluyveromyces genus is the most predominant. For the production of aromas, highlighting two strains of Kluyveromyces marxianus produces competitive quantities of compounds of great biotechnological interest such as 2-phenylethanol and 2-phenylethylacetate, without resorting to the genetic modification of yeasts or the optimization of the culture medium.
\end{abstract}

Keywords Mescal $\cdot$ Bioconversion $\cdot$ Aroma $\cdot$ L-Phenylalanine $\cdot$ Kluyveromyces marxianus

Olga Miriam Rutiaga-Quiñones omrutiaga@itdurango.edu.mx

Pablo Jaciel Adame-Soto

jaciel_as@hotmail.com

Elva Teresa Aréchiga-Carvajal elva.arechigacr@uanl.edu.mx

Mercedes G López

mercedes.lopez@cinvestav.mx

Silvia Marina González-Herrera smgonzalez@itdurango.edu.mx

Martha Rocio Moreno-Jiménez mrmoreno@itdurango.edu.mx

Norma Urtiz-Estrada urtizn@hotmail.com
1 Departamento de Ingenierías Química y Bioquímica, Tecnológico Nacional de México/ Instituto Tecnológico de Durango, Felipe Pescador 1803 Ote, Colonia Nueva Vizcaya, C.P. 34080 Durango, Durango, Mexico

2 Departamento de Microbiología e Inmunología, Unidad de Manipulación Genética del Laboratorio de Micología y Fitopatología. Unidad C. Facultad de Ciencias Biológicas, Universidad Autónoma de Nuevo León, C.P. 66451 San Nicolás de Los Garza, Nuevo León, Mexico

3 Departamento de Biotecnología y Bioquímica, Centro de Investigación y de Estudios Avanzados del IPN, Unidad Irapuato, Apartado Postal 629, C.P, 36821 Irapuato, Guanajuato, Mexico

4 Facultad de Ciencias Químicas-Laboratorio de Genética molecular, Universidad Juárez del Estado de Durango, Av. Veterinaria S/N Col. Valle del Sur. C.P., 34120 Durango, Durango, Mexico 


\section{Introduction}

The non-Saccharomyces yeasts are well recognized for their contribution to the aroma of fermentative beverages (Cordente et al. 2012; Ciani et al. 2016; Masneuf-Pomarede et al. 2016), especially wine. Their presence has also been reported in mescal and tequila. In Mexico, these alcoholic beverages are distinguished from each other, based on the agave species used in their production. For example, Agave tequilana Weber var. Azul (blue variety) is used for tequila, whereas Agave salmiana and Agave durangensis, (or Agave duranguensis) among others, are used for mescal production in various regions of Mexico (LappeOliveras et al. 2008; Páez-Lerma et al. 2010; De los RiosDeras et al. 2015; Kirchmayr et al. 2017). Mescal has elevated its economic importance in the last years (Kirchmayr et al. 2017). During the mescal production process, agave juice is naturally fermented by native yeasts, such as Saccharomyces, Pichia, Kluyveromyces, Candida, Debaryomyces, Hanseniaspora, Kloeckera, Schizosaccharomyces, Torulaspora, and Zygosaccharomyces (Lachance 1995; Díaz-Montaño et al. 2008; Escalante-Minakata et al. 2008). Previously published research on fermentations of agaves suggests that nonSaccharomyces yeasts have an important role in the initial fermentation process and influence the production of the volatile compounds (Lappe-Oliveras et al. 2008; Narváez-Zapata et al. 2010; Martell Nevárez et al. 2011). The potential use of these yeasts as inoculants has been described (Rodríguez-Sifuentes et al. 2014; Nuñez-Guerrero et al. 2016), as well as their participation in generating the volatile compounds in mescal, mainly esters (Martell Nevárez et al. 2011; Rutiaga-Quiñones et al. 2012; Hernández-Carbajal et al. 2013). Despite the increasing use of non-Saccharomyces yeasts in biotechnology, there are still many opportunities to improve native yeast exploration. These prospects have led to a great interest in further enhancing the number of non-Saccharomyces yeasts available, by selecting or developing strains with novel and attractive properties.

Flavor has a major impact on the quality perception of food and beverages, and fragrances are highly valued in the cosmetic and perfume industry. For natural aroma compounds that exist at low concentrations in their original sources, biotechnological processes represent an attractive alternative to the traditional preparation by extraction (Schrader et al. 2004). Due mainly to its sweet and rose-like taste and odor 2phenylethanol (2-PE) and its more fruit-like form, acetate ester 2-phenylethylacetate (2-PEA), find use in various flavor compositions (Fabre et al. 1998). For food applications, the rising demand for natural products means natural flavor compounds are increasingly becoming a necessity (Etschmann and Schrader 2006, Morrissey et al, 2015).

Both 2-PE and 2-PEA can be produced by de novo synthesis or from L-phenylalanine (L-Phe) by nonSaccharomyces yeast whole-cell biocatalysis via the Ehrlich pathway (Etschmann et al. 2003), (Etschmann and Schrader
2006). 2-PE can also be metabolized to 2-PEA by a transesterification reaction, which involves the transfer of a group of acetyl-coenzyme A acetate to the hydroxyl group of 2-PE (Hazelwood et al. 2008; Pires et al. 2014). When L-Phe is the sole nitrogen source in the medium, large amounts of 2-PE are accumulated. Several biotechnological processes are known for producing 2-PE, based on this pathway, and considerable progress has been made on the development of this process. In this context, yeast biodiversity may be greatly impacted by the production of different aroma products derived from primary and secondary metabolism. The diversity of nonSaccharomyces yeasts responsible for many of the volatile compounds found in mescal, in the state of Durango, Mexico, has not yet been evaluated. This research aimed to identify the non-Saccharomyces microbiota present in fermentations in three different mescal-producing regions and assess the production potential of aromatic compounds the addition of L-Phe as an inductor.

\section{Materials and methods}

\section{Yeast strains}

Thirty-four native strains, identified as non-Saccharomyces from Agave durangensis fermentation and obtained from the Collection of the Instituto Tecnologico de Durango, were isolated from three mescal-producing regions of Durango State, Mexico: Mezquital $\left(23^{\circ} 28^{\prime} 22^{\prime \prime} \mathrm{N}, 104^{\circ} 24^{\prime} 40^{\prime \prime} \mathrm{W}\right)$, Nombre de Dios ( $\left.23^{\circ} 51^{\prime} 00^{\prime \prime} \mathrm{N}, 104^{\circ} 14^{\prime} 00^{\prime \prime} \mathrm{W}\right)$, and Durango (24 $\left.01^{\prime} \mathrm{N}, 104^{\circ} 40^{\prime} \mathrm{W}\right)$. All yeast strains were conserved, as culture stock at $-20{ }^{\circ} \mathrm{C}$ in $30 \%(v / v)$ glycerol.

\section{Molecular identification}

\section{Growth conditions}

Yeast cells preserved in glycerol were first activated on YDP solid medium (glucose $20 \mathrm{~g} / \mathrm{L}$, casein peptone $20 \mathrm{~g} / \mathrm{L}$, yeast extract $10 \mathrm{~g} / \mathrm{L}$, and agar $20 \mathrm{~g} / \mathrm{L}$ ). DNA was then extracted at 24-h growth, using the method detailed by Sambrook and Russell (2001).

\section{Polymerase chain reaction and amplification}

Polymerase chain reaction (PCR) was carried out in $50-\mu \mathrm{L}$ volumes, using $2.0 \mu \mathrm{L}$ of DNA with ITS1 (5'-TCC GTA GGT GAA CCT GCG G-3') and ITS4 (5'-TCC TCC GCT TAT TGATAT $\mathrm{GC}-3^{\prime}$ ) primers to amplify the rDNA repeat unit that includes the 5.8S rRNA gene and the two non-coding regions designated the internal transcribed spacers (ITS1 and ITS4) (White et al. 1990). Amplification began with an initialization step of one cycle at $95{ }^{\circ} \mathrm{C}$ for $5 \mathrm{~min}$, then 35 cycles of 
$95^{\circ} \mathrm{C}$ for $1 \mathrm{~min}, 52^{\circ} \mathrm{C}$ for $2 \mathrm{~min}$, and $72{ }^{\circ} \mathrm{C}$ for $2 \mathrm{~min}$, followed by a final elongation at $72{ }^{\circ} \mathrm{C}$ for $10 \mathrm{~min}$ (White et al. 1990). The PCR product was electrophoresed on $1 \%$ agarose gel with TAE $0.5 \times$ buffer (Promega, Madison, WI, USA), at $95 \mathrm{~V}$ for $45 \mathrm{~min}$, stained with ethidium bromide (Sigma-Aldrich. St. Louis, MO, USA) and visualized under UV light (Benchtop UV transilluminator, Upland, CA, USA); DNA fragment sizes were determined using a 100-bp DNA ladder (Promega, USA). The PCR product was purified using $\mathrm{C}_{2} \mathrm{H}_{7} \mathrm{NO}_{2}$ and $\mathrm{C}_{2} \mathrm{H}_{6} \mathrm{O}(>$ 99\%) (Sigma-Aldrich). The rDNA sequences were acquired using an ABI PRISM Model 3730XL sequencer (Applied Biosystems, Inc., Foster City, CA, USA) at the National
Genomics for Biodiversity Laboratory (Langebio) of Cinvestav (Irapuato, Mexico).

\section{Phylogenetic analysis}

The obtained sequences were aligned using the MUSCLE program (https:/www.ebi.ac.uk/Tools/msa/muscle), and regions of local similarity between sequences were identified from the National Center for Biotechnology Information (NCBI) database of GenBank using the BLAST program (https://blast.ncbi.nlm.nih.gov/Blast). Phylogenetic analyses

Table 1 Strains used in this study

\begin{tabular}{|c|c|c|c|}
\hline Species & Strain & Locality & Accession no. \\
\hline Clavispora lusitaniae & ITD 0132 & Mezquital & MH282797 \\
\hline Kluyveromyces marxianus & ITD 0002 & Mezquital & MH282778 \\
\hline Kluyveromyces marxianus & ITD 0003 & Mezquital & MH282779 \\
\hline Kluyveromyces marxianus & ITD 0090 & Mezquital & MF797638.1 \\
\hline Kluyveromyces marxianus & ITD 0091 & Mezquital & MH282784 \\
\hline Kluyveromyces marxianus & ITD 0092 & Mezquital & MH282785 \\
\hline Kluyveromyces marxianus & ITD 0093 & Mezquital & MH282786 \\
\hline Kluyveromyces marxianus & ITD 0128 & Mezquital & MH282787 \\
\hline Kluyveromyces marxianus & ITD 0141 & Mezquital & MH282790 \\
\hline Kluyveromyces marxianus & ITD 0142 & Mezquital & MH282791 \\
\hline Kluyveromyces marxianus & ITD 0145 & Mezquital & MH282792 \\
\hline Kluyveromyces marxianus & ITD 0211 & Mezquital & MH282793 \\
\hline Kluyveromyces sp. & ITD 0040 & Mezquital & MH282781 \\
\hline Kluyveromyces sp. & ITD 0041 & Mezquital & MH282782 \\
\hline Kluyveromyces sp. & ITD 0089 & Mezquital & MH282783 \\
\hline Kluyveromyces sp. & ITD 0136 & Mezquital & MH282788 \\
\hline Kluyveromyces sp. & ITD 0137 & Mezquital & MH282789 \\
\hline Torulaspora delbrueckii & ITD 0110 & Mezquital & MH282795 \\
\hline Torulaspora delbrueckii & ITD 0129 & Mezquital & MH282796 \\
\hline Saccharomyces cerevisiae & ITD 0109 & Mezquital & MH282794 \\
\hline Clavispora lusitaniae & ITD 0095 & Nombre de Dios & MH282804 \\
\hline Clavispora lusitaniae & ITD 0099 & Nombre de Dios & MH282805 \\
\hline Clavispora lusitaniae & ITD 0103 & Nombre de Dios & MH282806 \\
\hline Clavispora lusitaniae & ITD 0104 & Nombre de Dios & MH282807 \\
\hline Clavispora lusitaniae & ITD 0107 & Nombre de Dios & MH282808 \\
\hline Kluyveromyces marxianus & ITD 0102 & Nombre de Dios & MH282801 \\
\hline Kluyveromyces marxianus & ITD 0264 & Nombre de Dios & MH282802 \\
\hline Kluyveromyces marxianus & ITD 0268 & Nombre de Dios & MH282803 \\
\hline Kluyveromyces sp. & ITD 0046 & Nombre de Dios & MH282798 \\
\hline Kluyveromyces sp. & ITD 0048 & Nombre de Dios & MH282799 \\
\hline Kluyveromyces sp. & ITD 0049 & Nombre de Dios & MH282800 \\
\hline Kluyveromyces marxianus & ITD 0069 & Durango & MH282810 \\
\hline Kluyveromyces sp. & ITD 0062 & Durango & MH282809 \\
\hline Kluyveromyces dobzhanskii & ITD 0157 & Durango & MH282811 \\
\hline Kluyveromyces marxianus & CBS 600 & Reference & KY103809.1 \\
\hline
\end{tabular}


were conducted in MEGA7 Program. The sequences were deposited in GenBank.

\section{Production of volatile organic compounds}

\section{Chemicals and reagents}

L-Phe (<98\%), 2-PE ( $>99 \%)$, and 2-PEA ( $>99 \%)$ were purchased from Sigma-Aldrich. $\mathrm{Na}_{2} \mathrm{HPO}_{4} \cdot 2 \mathrm{H}_{2} \mathrm{O}, \mathrm{MgSO}_{4} \cdot 7 \mathrm{H}_{2} \mathrm{O}$ (Caisson Laboratory In., Smithfield, UT, USA), and citric acid were obtained from Fermont (Mexico City, Mexico). Glucose, yeast extract and casein peptone came from BD Bioxon (Mexico City, Mexico).

\section{Bioconversion}

The strains were pre-grown in 125 -mL baffled Erlenmeyer flasks (Corning, Inc., USA) with vented top, containing a $50-\mathrm{mL}$ operative volume of standard yeast medium YPD broth $(20 \mathrm{~g} / \mathrm{L}$ glucose, $20 \mathrm{~g} / \mathrm{L}$ casein peptone, and $10 \mathrm{~g} / \mathrm{L}$ yeast extract), at $30^{\circ} \mathrm{C}$ for $12 \mathrm{~h}$ and $120 \mathrm{rpm}$. For fermentation, the strains were inoculated at a concentration of $10^{7}$ cells $/ \mathrm{mL}$ and incubated at $30{ }^{\circ} \mathrm{C}$ for $24 \mathrm{~h}$ and $120 \mathrm{rpm}$. Duplicate experiments were done for induction with $\mathrm{L}-\mathrm{Phe}(9 \mathrm{~g} / \mathrm{L})$, in which the culture medium contained $30 \mathrm{~g} / \mathrm{L}$ glucose, $35 \mathrm{~g} / \mathrm{L}$ $\mathrm{Na}_{2} \mathrm{HPO}_{4} \cdot 2 \mathrm{H}_{2} \mathrm{O}, 10.5 \mathrm{~g} / \mathrm{L}$ citric acid, $0.5 \mathrm{~g} / \mathrm{L} \mathrm{MgSO}_{4} .7 \mathrm{H}_{2} \mathrm{O}$, and $0.17 \mathrm{~g} / \mathrm{L}$ yeast extract, in a $50-\mathrm{mL}$ medium, in a $125-\mathrm{mL}$ Erlenmeyer flask (Etschmann et al. 2004). The yeast Kluyveromyces marxianus CBS 600 (KY103809.1) was included as a reference.

\section{Gas chromatography-mass spectrometry analysis}

The volatile organic compounds were extracted by headspace solid-phase micro-extraction (HS-SPME) with a divinylbenzene/carboxen/polydimethylsiloxane fiber (Supelco, Bellefonte, PA, USA). One milliliter of the sample was taken from each fermentation at $24 \mathrm{~h}$, placed inside a $4-\mathrm{mL}$ vial, sealed tightly with a screw-top septum-containing cap, and allowed to stand at $35{ }^{\circ} \mathrm{C}$ for $1 \mathrm{~h}$. The SPME needle was then inserted through the septum, the holder was secured, and the fiber was exposed to the headspace. After $1 \mathrm{~h}$ of sampling at $35^{\circ} \mathrm{C}$, the fiber was retracted and immediately inserted into the inlet of a HP 5890 Series II GC instrument directly coupled to an HP 5972 mass-selective detector (Hewlett-Packard, Palo Alto, CA, USA) and equipped with an HP-FFAP capillary column $(25 \mathrm{~m} \times$ $0.320 \mathrm{~mm}$ i.d., film thickness $0.50 \mathrm{~m}$; Hewlett-Packard), for thermal desorption. The injection was accomplished by desorption of the fiber at $230{ }^{\circ} \mathrm{C}$ for $6 \mathrm{~min}$ with the injector operated in the splitless mode for $1 \mathrm{~min}$. An additional 5-min exposure in the injection port allowed the fiber to be cleaned of any compound that may not have been desorbed during the initial minute (Calvo-Gómez et al. 2004). Helium was used as the carrier gas, at a linear flow of $2 \mathrm{~mL} / \mathrm{min}$. The injector and detector temperatures were 230 and $260{ }^{\circ} \mathrm{C}$, respectively. The oven temperature was increased from 40 to $240{ }^{\circ} \mathrm{C}$, using the following program: the initial temperature was maintained for $3 \mathrm{~min}$, ramped at $4{ }^{\circ} \mathrm{C} / \mathrm{min}$ to $100{ }^{\circ} \mathrm{C}$, held for $1 \mathrm{~min}$, and then ramped at $4{ }^{\circ} \mathrm{C} / \mathrm{min}$ to $240^{\circ} \mathrm{C}$ and held for $10 \mathrm{~min}$. The ionization voltage was $70 \mathrm{eV}$. All the assays were performed twice. The analyzed compounds were identified by comparing their mass spectra with those in the NIST database (Calvo-Gómez et al. 2004). In addition, the volatile compounds of interest (2-PE and 2-PEA) were quantified by standard curves.

\section{Statistical analysis}

Data of the volatile compounds, 2-PE and 2-PEA, were evaluated by the HSD-Tukey-Kramer comparison test, at $\alpha=$ 0.01 All statistical analyses were done using JMP software version 13.2 (SAS Institute, Inc., NC, USA).

\section{Result and discussion}

\section{Molecular identification and phylogenetic analyses}

Table 1 indicates the molecular identification of the studied strains, for each geographic region. These strains corresponded to six different genera: Clavispora lusitaniae, Kluyveromyces sp., Kluyveromyces dobzhanskii, Kluyveromyces marxianus, Saccharomyces cerevisiae, and Torulaspora delbrueckii. Previous investigations of the yeasts associated with mescal production in Mexico, described the presence of nonSaccharomyces strains, such as K. marxianus, C. lusitaniae, and Pichia fermentans from Agave salmiana fermentation, in San Luis Potosí State (Escalante-Minakata et al. 2008). In another Vinata, from the same region, the non-Saccharomyces yeasts were: K. marxianus, Pichia kluyveri, Zygosaccharomyces bailii, C. lusitaniae, T. delbrueckii, and Candida ethanolica (VerdugoValdez et al. 2011). In mescal produced using the species Agave durangensis in Durango, the predominant non-Saccharomyces yeasts belonged to Candida genus, including Candida lusitaniae, Candida kefir, Candida glabrata, Candida laurentii, and

Fig. 1 Neighbor-joining trees were constructed from the evolutionary distance data for ITSI-5.85 rDNA-ITS2. The percentage of replicate trees in which the associated taxa clustered together in the bootstrap test (1000 replicates). a Kluyveromyces marxianus tree of group one. b Kluyveromyces dobhzankii tree. c Kluyveromyces sp of group two tree. The accession numbers of reference sequences used in this tree are as follows: $K$. nonfermentans (AB011512.1), K. lactis (AB011515.1), K. wickerhamii (AB011521.1), K. aestuarii (AB011513.1), K. marxianus (AB011518.1), K. marxianus (MH045720.1), K. marxianus (MH045721.1), K. marxianus (MH045719.1), K. marxianus (MG966429.1), K. marxianus (JX174415.1), K. dobzhanskii (ABO11514.1), and D. hansenii (JQ912667.1). Evolutionary analyses were conducted in MEGA7 
a

ITD0093(MH282786)

K-marxianus(AB011518.1)

ITD0002(MH282778)

ITD0102(MH282801)

ITD0091(MH282784)

ITD0003(MH282779)

ITD0141(MH282790)

ITD0145(MH282792)

ITD0069(MH282810)

ITD0092(MH282785)

21 ITD0128(MH282787)

ITD0142(MH282791)

ITD0211(MH282793)

ITD0264(MH282802)

ITD0268(MH282803)

ITD0090(MF797638.1)

Kmarxianus-CHP7(MH045719.1)

Km-KDLYH1-1(JX174415.1)

Km-CDA2(MG966429.1)

14 Kmarxianus-CDB5(MH045721.1)

Kmarxianus-CDB1(MH045720.1)

28 K-dobzhanskii(AB011514.1)

$41 . \mid \begin{aligned} & \text { K-nonfermentans(AB011512.1) } \\ & \text { K-lactis(AB011515.1) }\end{aligned}$

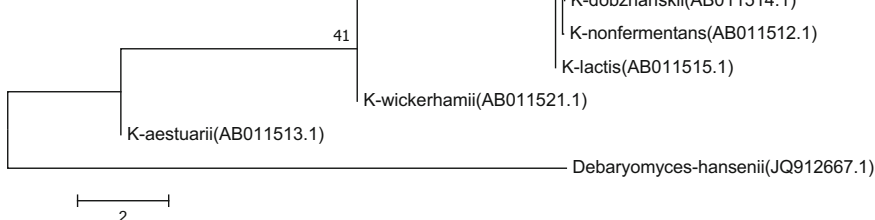

$\longmapsto 2 \longmapsto$

b

48

${ }_{48} \mathrm{~K}$-nonfermentans(AB011512.1)

16 K

K-aestuarii(AB011513.1)

K-lactis(AB011515.1)

$\left.77\right|_{\text {K-wickerhamii(AB011521.1) }}$

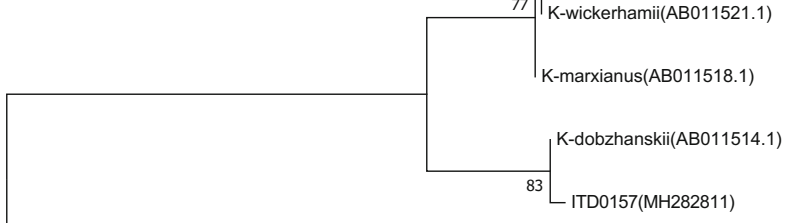

Debaryomyces-hansenii(JQ912667.1)

$\longmapsto 2$

C

ITD0049(MH282800)

ITD0062(MH282809)

ITD0048(MH282799)

21 ITD0046(MH282798)

ITD0041(MH282782)

ITD0040(MH282781)

25 ITD0037(MH282780)

75 ITD0089(MH282783)

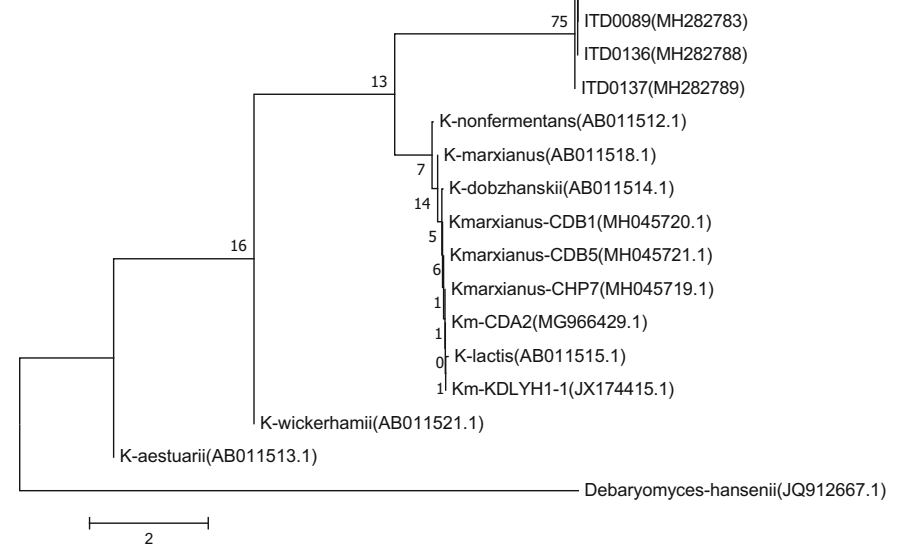


Candida tropicalis (Páez-Lerma et al. 2010). Equally, in Durango State, Páez-Lerma et al. (2013) observed diverse microorganisms at the beginning of fermentation: $S$. cerevisiae, T. delbrueckii, K. marxianus, Candida diversa, P. fermentans, and Hanseniaspora uvarum, but only T. delbrueckii and $S$. cerevisiae were found at the end of the fermentations. Recently, Kirchmayr et al. (2017) mentioned K. marxianus, Zygosaccharomyces rouxii, Z. bisporus, T. delbrueckii, and Pichia membranifaciens as the main microbiota present, after $S$. cerevisiae, during mescal production in Oaxaca State. In our study, Mezquital region presented the greatest number and diversity of isolated non-Saccharomyces, which included $K$. marxianus, T. delbrueckii, and C. lusitaniae. Both $K$. marxianus and $C$. lusitaniae were also detected in mescal from Nombre de Dios. In fermentation of agave in Durango, the species identified were $K$. marxianus and $K$. dobzhanskii. This article is the first report where the strain $K$. dobzhanskii has been found in natural fermentation processes. This genus has been cataloged as the closest Kluyveromyces lactis relative of wild or native strains, so it has been used for modeling population genetics (Belloch et al. 1997, 2002; Sukhotina et al. 2006; Lane and Morrissey 2010).

In phylogenetic studies of Kluyveromyces strains (Fig. 1), three groups were recognized. The first two groups comprised strains directly related to the genus $K$. marxianus and $K$. dobzhanskii, respectively (Fig. 1a, b). The third group had direct relationship to the genera of the Kluyveromyces family (Fig. 1c). These strains were present in all the regions, accounting for 35\% (Mezquital), 50\% (Nombre de Dios), and 30\% (Durango) of the total of the isolated Kluyveromyces strains and can represent a particular genetic diversity for $K$. marxianus strains isolated from the fermentation process during the production of mescal. In a recent study of the genetic diversity of the genus $K$. marxianus, all the isolates from a lactic environment were either diploid or triploid, whereas non-lactic isolates were haploid (Ortiz-Merino et al. 2018). Additionally, the authors distinguished three clades, of which the strain UFS-Y2791, isolated from American agave juice and representing the third clade, proved to be more diverse than the others (Ortiz-Merino et al. 2018). So far, only the presence of $K$. marxianus strains from different mescal production has been reported in the literature, indicating that the current work is the first to show that $K$. marxianus strains isolated from agave fermentation (mescal or tequila) have distinct genetic differences between them. PáezLerma et al. (2013) noted these differences with $S$. cerevisiae strains in wine.

Additionally, phylogenetic analysis among the Clavispora lusitaniae yeasts from this study (Fig. 2a) evidenced the genetic variability between strains of Clavispora lusitaniae. These yeasts were found predominantly in fermentations from Nombre de Dios, with $45 \%$ of the strains identified as C. lusitaniae. PérezBrito et al. (2015) characterized the great genetic diversity of C. Iusitaniae strains isolated from the fermentation of Agave fourcroydes Lem. There are numerous accounts of this species during the different stages of processing and fermentation of Agave to obtain traditional Mexican beverages, such as "pulque," mescal, and tequila (Rodrigues de Miranda 1979; Lachance 1995; Lappe et al. 2004; De León Rodríguez et al. 2008; Lappe-Oliveras et al. 2008; Páez-Lerma et al. 2010; Kurtzman et al. 2011; Verdugo-Valdez et al. 2011), where its presence has been associated with the sensory qualities of these beverages (Escalante-Minakata et al. 2008).

The species present in relatively low quantity was T. delbrueckii, found only in the region of the Mezquital. Figure $2 \mathrm{~b}$ shows the phylogenetic tree for strains ITD0110 and ITD0129. These strains have been linked to a high production of volatile compounds that impart unique characteristics to beverages, such as mescal, and also other flavor compounds, including terpenoids, esters, higher alcohols, glycerol acetaldehyde, acetic acid, and succinic acid (Moreira et al. 2005; Jolly et al. 2014). Rutiaga-Quiñones et al. (2012) profiled the volatile compounds in Agave duranguensis juice supplemented with $\mathrm{NH}_{4} \mathrm{Cl}$ and fermented with the yeast T. delbrueckii ITD0110. However, the genetic diversity present in this genus was not established. Nuñez-Guerrero et al. (2016) isolated $S$. cerevisiae, $T$. delbrueckii, and $K$. marxianus from $A$. duranguensis fermentation and proposed the use of a mixture of $75 \% \mathrm{~S}$. cerevisiae and $25 \% \mathrm{~T}$. delbrueckii as an inoculant to make mescal.

\section{Production of volatile organic compounds}

Table 2 presents the volatile compounds produced by the nonSaccharomyces yeasts studied in this work. In general, all strains were producers of esters, fatty acids esters, and higher alcohols. Esters are key flavor compounds in fermented beverages, like mescal. Among the acetate esters, the synthesis of ethyl acetate, which is responsible for the bouquet and desirable fruity flavors, depends on the ethanol concentration while the synthesis of isoamyl acetate, isobutyl acetate and 2-PEA, relies on the concentration of their corresponding higher alcohol, by the action of an alcohol acetyltransferase (Gethins et al. 2015; Loser et al. 2014).

The ethyl esters of short-chain fatty acids present are 2phenylethyl butyrate and Phenylethyl propionate, synthesized from 2-PE and short-chain fatty acids. Phenylethyl propionate is an ester desirable in wine, due to its floral aroma (Beckner Whitener et al. 2015; Padilla et al. 2016). The formation of benzaldehyde from Phe has been studied in several microorganisms, such as Pseudomonas putida and the white rot fungi, Tremetes suaveolens, Polyporus tuberaste, Bierkandera adusteand, and Phanerochaete chrysosporium (Rojas et al. 2001; Liu et al. 2004). Hence, these yeasts seem to have benzaldehyde production potential. The principal volatile compounds found were 2$\mathrm{PE}$, which is considered to be one of the most important aromatic alcohols, and 2-PEA. The higher alcohols are predominantly 

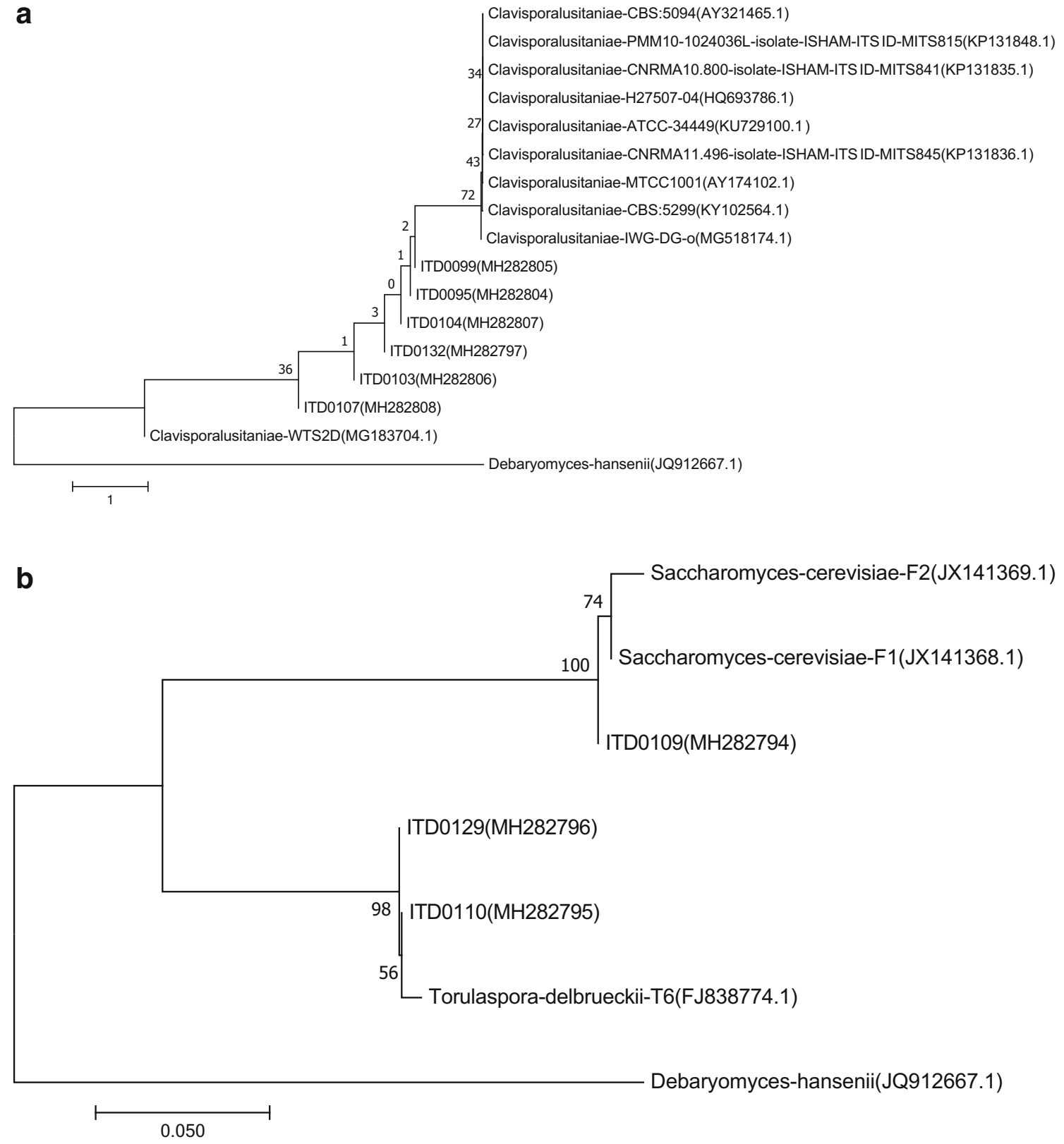

Fig. 2 Neighbor-joining trees were constructed from the evolutionary distance data for ITSI-5.85 rDNA-ITS2. The percentage of replicate trees in which the associated taxa clustered together in the bootstrap test (1000 replicates). a Clavispora lusitaniae tree. b $S$. cerevisiae-T. delbrueckii tree. The accession numbers of reference sequences used in these trees are as follows: C. lusitaniae (AY321465.1), C. lusitaniae (KP131848.1), C. lusitaniae (KP131835.1), C. lusitaniae

formed by yeast during fermentation by the Ehrlich pathway, involving amino acid degradation, particularly Phe (Hazelwood et al. 2008; Styger et al. 2011) but can also be synthesized from glucose via pyruvate (Cordente et al. 2012). The Ehrlich pathway involves three steps: phenylpyruvate is decarboxylated to phenylacetaldehyde, then reduced to 2-PE (Etschmann and Schrader 2006), and finally esterified to 2-PEA.
(HQ693786.1), C. Iusitaniae (KU729100.1), C. lusitaniae (KP131836.1), C. lusitaniae (AY174102.1), C. lusitaniae (KY102564.1), C. lusitaniae MG518174.1), C. lusitaniae (MG183704.1), S. cerevisiae (JX141369.1), S. cerevisiae (JX141368.1), T. delbrueckii (FJ838774.1), and D. hansenii (JQ912667.1). Evolutionary analyses were conducted in MEGA7

The production of volatile organic compounds (2-PE and 2-PEA) presented significant statistical differences between by non-Saccharomyces yeasts is shown in Table 3.The most productive yeasts, in terms of 2-PE, were as follows: Kluyveromyces marxianus (ITD0090, ITD0091), as well as the yeasts Kluyveromyces sp. (ITD0046, ITD0089 and ITD0040), Kluyveromyces dobzhanskii ITD0157, and 
Table 2 Volatile metabolites produced by non-Saccharomyces strains

\begin{tabular}{llll}
\hline Metabolite & $\mathrm{R} T$ & $\mathrm{~m} / \mathrm{z}$ & Sensorial description \\
\hline Ethyl acetate & 0.95 & $61-70-73-88$ & Pineapple, sweet, and fruit \\
Isoamyl acetate & 4.04 & $55-70-87$ & Banana, sweet and fruit \\
Isoamyl alcohol & 6.24 & $55-70-87$ & Alcohol, banana, and malt \\
Benzaldehyde & 16.36 & $51-77-106$ & Almond, burnt sugar, cherry, and sweet \\
2-Phenylethylacetate & 22.72 & $121-104-91-77$ & Floral, fruit, honey, and roses \\
2-Phenylethyl butyrate & 23.68 & $117-104-91-77-71-65$ & Yeast, strawberry, floral, and sweet \\
Phenylethyl propionate & 23.79 & $104-91-77-57$ & Floral, red fruit, and honey \\
2-Phenylethanol & 24.22 & $103-91-77-65-51$ & Roses, fresh, and leafy \\
\hline
\end{tabular}

Clavispora lusitaniae ITD0107. K. marxianus yeast ITD0090 can be classified as the largest producer of 2-PE, even when compared with the most studied yeast $K$. marxianus CBS600 (Table 3). The concentrations obtained were similar to that reported by Etschmann et al. (2003) (890 mg/L in a molasses-based medium). Eshkol et al. (2009) evaluated the potential of stress-tolerant Saccharomyces strains to produce 2-PE under inductive conditions (Phe addition) and detected the concentrations between 340 and $460 \mathrm{mg} / \mathrm{L}$ at 48 -h incubation, but these concentrations increased to 540 and $850 \mathrm{mg} / \mathrm{L}$ with selected yeast, when conditions were optimized with $10 \mathrm{~g} / \mathrm{L}$ Phe addition, which were very similar quantities to those reported here, without the optimization process. In a related study, with the $K$. marxianus strain CBS6556, the optimization of the grape must culture medium with $3 \mathrm{~g} / \mathrm{L}$ of LPhe improved the 2-PE titer of $0.39 \mathrm{~g} / \mathrm{L}$ after $84 \mathrm{~h}$ of culture to $0.47 \mathrm{~g} / \mathrm{L}$ (Garavaglia et al. 2007). Mei et al. (2009) also used a yeast Saccharomyces cerevisiae BD and reported in situ product adsorption techniques, to obtain a better performance regarding the biotransformation of L-phenylalanine to 2phenylethanol, reaching a concentration of $4.65 \mathrm{~g} / \mathrm{L}$ of 2-PE with a content of $10 \mathrm{~g} / \mathrm{L}$ of L-Phe in the medium. Chreptowicz et al. (2016) with yeast not genetically modified strain Saccharomyces cerevisiae JM2014 was isolated from a fermented milk drink (Turkey), producing a total concentration of $3.60 \mathrm{~g} / \mathrm{L}$ of 2-PE after $72-\mathrm{h}$ incubation at $30{ }^{\circ} \mathrm{C}$ batch culture with a medium containing $5 \mathrm{~g} / \mathrm{L}$ of L-Phe in a 4-L bioreactor at laboratory scale. Recently, De Lima et al. (2018) evaluated the potential of yeast strain $K$. marxianus CCT 7735 in the 2-PE production and reported a production of $2.47 \mathrm{~g} / \mathrm{L}$ of $2-\mathrm{PE}$, with the optimization in the medium through the optimal conditions achieving thus a production of $3.44 \mathrm{~g} / \mathrm{L}$ of 2-PE. Lu et al. (2016) showed the 2-PE titer in a batch fermentation with the stress-tolerant yeast Candida glycerinogenes WL2002-5, reaching $5 \mathrm{~g} / \mathrm{L}$ from L-Phe, under optimized culture conditions. Genetic modification strategies have also been considered, to further increase 2-PE production, such as $A R O 8$ and $A R O 10$ overexpression in $S$. cerevisiae SPO 10 yeast the 2-PE reached $2.61 \mathrm{~g} / \mathrm{L}$ after $60 \mathrm{~h}$ of cultivation (Yin et al. 2015).

Chreptowicz et al. (2018) reported yeast strains capable of producing over $2 \mathrm{~g} / \mathrm{L} 2-\mathrm{PE}$ through the L-Phe biotransformation in standard medium for 72-h batch cultures. Clavispora lusitaniae WUT17 strain reached the levels of $2.04 \mathrm{~g} / \mathrm{L}$ of 2-PE in a standard medium and $0.95 \mathrm{~g} / \mathrm{L}$ of $2-$ $\mathrm{PE}$ in an organic waste-based medium, which is superior to the one reported by Etschmann et al. (2003) of $0.33 \mathrm{~g} / \mathrm{L}$. It is well known that 2-PE synthesis is carried out by the Ehrlich pathway in yeast, such as K. marxianus and Yarrowia lipolytica (Fabre et al. 1998; Celińska et al. 2013). In a recent study, González et al. (2018) screened the 2-PE production potential of some non-Saccharomyces yeasts and discovered a 2-PE productive yeast (T. delbrueckii). However, in all cases, non-Saccharomyces species produce lower quantities than $S$. cerevisiae, indicating that the Ehrlich pathway may not be as active in non-Saccharomyces species as in Saccharomyces, at least under nitrogen-limiting conditions. Rutiaga-Quiñones et al. (2012) revealed the nonSaccharomyces yeasts potential for volatile compounds, particularly in A. duranguensis juice for mescal production; in this study, the strains $T$. delbrueckii ITD0110 and $K$. marxianus ITD0211 showed to be more productive of 2PE under nitrogen-limiting conditions that the strain S. cerevisiae ITD0109. A possible theory for our observations, when the fermentations of different strains induced with L-Phe as the only source of nitrogen were evaluated, is that the Ehrlich route is working on these strains, but the metabolic plasticity differs for each of the strains studied. These results allow to raise genetic and biochemical differences between the strains of wine production and mescal, but additional studies are required to elucidate and describe them.

The Table 3 illustrates that 2-PEA production presents significant difference for each strain where that highlighting the K. marxianus strains (ITD0040, ITD0090, ITD0102, and ITD0211). A previous research by Rojas et al. (2001) described a very productive $H$. guilliermondii yeast, with a 2 PEA production of $83.83-163.8 \mathrm{mg} / \mathrm{L}$, when using 2-PE as induction conditions and in the presence of extraction solvent. The present results describe a difference in the production potential from L-Phe induction, among all the strains studied, highlighting two strains, $K$. marxianus ITD0090 and $K$. marxianus ITD0211, due to the potential to overproduce 2-PE and 2-PEA, respectively. Etschmann et al. (2005) 
Table 3 Production 2phenylethanol and 2phenylethylacetate obtained by different yeast strains nonSaccharomyces by HS-SPME

\begin{tabular}{|c|c|c|c|c|c|c|}
\hline \multirow[t]{2}{*}{ Species } & \multirow[t]{2}{*}{ ID strains } & \multicolumn{2}{|c|}{$\begin{array}{l}\text { Production of 2-PE (mg/ } \\
\text { L) }\end{array}$} & \multirow[t]{2}{*}{ ID Strains } & \multicolumn{2}{|c|}{$\begin{array}{l}\text { Production of 2-PEA } \\
(\mathrm{mg} / \mathrm{L})\end{array}$} \\
\hline & & Mean & S.d & & Mean & S.d \\
\hline \multirow[t]{6}{*}{ Clavispora lusitaniae } & ITD0107 & 764.80 & $62.64^{\mathrm{a}-\mathrm{f}}$ & ITD0095 & 22.43 & $2.55^{\mathrm{h}-\mathrm{j}}$ \\
\hline & ITD0095 & 636.60 & $47.41^{\mathrm{b}-\mathrm{g}}$ & ITD0107 & 17.17 & $4.52^{\mathrm{h}-\mathrm{j}}$ \\
\hline & ITD0132 & 511.89 & $2.23^{\mathrm{d}-\mathrm{j}}$ & ITD0104 & 13.16 & $1.14^{\mathrm{i}, \mathrm{j}}$ \\
\hline & ITD0104 & 394.74 & $42.54^{\mathrm{g}-\mathrm{j}}$ & ITD0099 & 12.14 & $0.29^{\mathrm{i}, \mathrm{j}}$ \\
\hline & ITD0099 & 370.89 & $10.13^{\mathrm{g}-\mathrm{j}}$ & ITD0132 & 11.89 & $0.19^{\mathrm{i}, \mathrm{j}}$ \\
\hline & ITD0103 & 357.54 & $29.41^{g-j}$ & ITD0103 & 9.20 & $1.06^{\mathrm{j}}$ \\
\hline \multirow[t]{17}{*}{ Kluyveromyces marxianus } & ITD0090 & 1024.46 & $306.38^{\mathrm{a}}$ & ITD0211 & 203.53 & $3.52^{\mathrm{a}}$ \\
\hline & ITD0091 & 848.37 & $112.28^{\mathrm{a}-\mathrm{c}}$ & ITD0102 & 202.07 & $26.28^{\mathrm{a}}$ \\
\hline & ITD0211 & 630.81 & $7.13^{\mathrm{b}-\mathrm{h}}$ & CBS600 & 166.24 & $0.40^{\mathrm{a}-\mathrm{c}}$ \\
\hline & ITD0102 & 618.88 & $46.90^{\mathrm{b}-\mathrm{h}}$ & ITD0091 & 136.49 & $28.48^{\mathrm{a}-\mathrm{d}}$ \\
\hline & ITD0093 & 596.41 & $26.16^{\mathrm{b}-\mathrm{i}}$ & ITD0128 & 134.27 & $13.52^{\mathrm{a}-\mathrm{e}}$ \\
\hline & ITD0092 & 564.33 & $1.90^{\mathrm{c}-\mathrm{i}}$ & ITD0264 & 108.66 & $5.95^{\mathrm{b}-\mathrm{f}}$ \\
\hline & ITD0069 & 507.95 & $33.82^{\mathrm{e}-\mathrm{j}}$ & ITD0002 & 108.54 & $24.08^{\mathrm{b}-\mathrm{f}}$ \\
\hline & ITD0268 & 446.14 & $29.03^{\mathrm{f}-\mathrm{j}}$ & ITD0069 & 89.36 & $2.79^{\mathrm{d}-\mathrm{h}}$ \\
\hline & ITD0145 & 436.08 & $28.34^{\mathrm{g}-\mathrm{j}}$ & ITD0142 & 86.96 & $11.79^{\mathrm{d}-\mathrm{i}}$ \\
\hline & ITD0142 & 391.87 & $3.21^{\mathrm{g}-\mathrm{j}}$ & ITD0092 & 79.61 & $0.47^{\mathrm{d}-\mathrm{j}}$ \\
\hline & ITD0041 & 383.35 & $2.05^{\mathrm{g}-\mathrm{j}}$ & ITD0268 & 71.79 & $12.81^{\mathrm{d}-\mathrm{j}}$ \\
\hline & ITD0128 & 380.32 & $3.41^{\mathrm{g}-\mathrm{j}}$ & ITD0145 & 71.30 & $4.80^{\mathrm{d}-\mathrm{j}}$ \\
\hline & ITD0003 & 371.87 & $19.70^{\mathrm{g}-\mathrm{j}}$ & ITD0141 & 60.54 & $2.56^{\mathrm{e}-\mathrm{j}}$ \\
\hline & ITD0141 & 310.26 & $5.96^{\mathrm{h}-\mathrm{j}}$ & ITD0093 & 56.74 & $4.87^{\mathrm{f}-\mathrm{j}}$ \\
\hline & ITD0002 & 273.18 & $63.30^{\mathrm{i}, \mathrm{j}}$ & ITD0003 & 12.10 & $1.85^{\mathrm{i}, \mathrm{j}}$ \\
\hline & ITD0264 & 217.89 & $3.97^{\mathrm{j}}$ & ITD0041 & 107.02 & $4.44^{\mathrm{b}-\mathrm{f}}$ \\
\hline & CBS600* & 806.30 & $55.86^{\mathrm{a}-\mathrm{e}}$ & ITD0090 & 177.36 & $64.88^{\mathrm{a}, \mathrm{b}}$ \\
\hline \multirow[t]{9}{*}{ Kluyveromyces sp. } & ITD0046 & 901.78 & $126.87^{\mathrm{a}, \mathrm{b}}$ & ITD0040 & 165.34 & $28.25^{\mathrm{a}-\mathrm{c}}$ \\
\hline & ITD0089 & 832.62 & $60.34^{\mathrm{a}-\mathrm{d}}$ & ITD0089 & 133.57 & $22.87^{\mathrm{a}-\mathrm{e}}$ \\
\hline & ITD0040 & 804.55 & $9.92^{\mathrm{a}-\mathrm{e}}$ & ITD0062 & 131.25 & $2.70^{\mathrm{a}-\mathrm{f}}$ \\
\hline & ITD0137 & 643.05 & $22.86^{\mathrm{b}-\mathrm{g}}$ & ITD0046 & 116.48 & $6.13^{\mathrm{b}-\mathrm{f}}$ \\
\hline & ITD0049 & 559.25 & $47.84^{\mathrm{c}-\mathrm{i}}$ & ITD0136 & 98.46 & $9.66^{\mathrm{c}-\mathrm{g}}$ \\
\hline & ITD0037 & 516.94 & $51.03^{\mathrm{d}-\mathrm{j}}$ & ITD0037 & 91.82 & $15.70^{\mathrm{c}-\mathrm{h}}$ \\
\hline & ITD0048 & 492.63 & $4.10^{\mathrm{e}-\mathrm{j}}$ & ITD0049 & 67.32 & $9.22^{\mathrm{d}-\mathrm{j}}$ \\
\hline & ITD0136 & 448.58 & $19.08^{\mathrm{f}-\mathrm{j}}$ & ITD0048 & 62.72 & $7.84^{\mathrm{d}-\mathrm{j}}$ \\
\hline & ITD0062 & 442.38 & $24.29^{f_{-j}}$ & ITD0137 & 59.89 & $6.05^{\mathrm{e}-\mathrm{j}}$ \\
\hline Kluyveromyces dobzhanskii & ITD0157 & 789.36 & $55.07^{\mathrm{a}-\mathrm{e}}$ & ITD0157 & 122.41 & $9.00^{\mathrm{b}-\mathrm{f}}$ \\
\hline Saccharomyces cerevisae & ITD0109 & 491.38 & $70.73^{e-j}$ & ITD0109 & 8.97 & $0.37^{\mathrm{j}}$ \\
\hline \multirow[t]{2}{*}{ Torulaspora delbruekii } & ITD0110 & 676.55 & $27.27^{\mathrm{b}-\mathrm{g}}$ & ITD0110 & 25.50 & $7.37^{\mathrm{g}-\mathrm{j}}$ \\
\hline & ITD0129 & 506.33 & $23.75^{\mathrm{e}-\mathrm{j}}$ & ITD0129 & 20.18 & $2.48^{\mathrm{h}-\mathrm{j}}$ \\
\hline
\end{tabular}

Media with the same letter are not significantly different according to the HSD-Tukey-Kramer comparison test $(\alpha=0.01)$ described that the yeast $K$. marxianus CBS600 produced $1.3 \mathrm{~g} / \mathrm{L}$ of 2 -PEA, and a maximum of $4 \mathrm{~g} / \mathrm{L}$, using an organophilic pervaporation technique for continuous in situ product removal (ISPR) in a previously optimized medium. The production of 2-PEA by starter of Hanseniaspora vinaeSaccharomyces cerevisiae has been reported, where the concentration was 0.81 to $1.70 \mathrm{mg} / \mathrm{L}$ in wine; 2-phenylethyl acetate levels in wine vary from traces to $0.96 \mathrm{mg} / \mathrm{L}$ whereas its aroma threshold is around $0.25 \mathrm{mg} / \mathrm{L}$ (Viana et al. 2011). Also, a patent has been granted for the production of 2-PEA in anaerobic conditions with the Kluyveromyces marxianus KY3 strain with a production of $435 \mathrm{mg} / \mathrm{L}$ (Chang et al. 2014). Recently, it has been reported solid-state fermentation processes (SSF) for 2-PEA and 2-PE production using agroindustrial residue sugarcane bagasse as sole carbon source for the biotransformation of L-phenylalanine using 
Kluyveromyces marxianus strain as inoculum, showing effective results as in other systems submerged fermentation (Martínez et al. 2018).

Guo et al. (2017) designed and expressed a 2-PEA biosynthetic pathway in E. coli and in shake flask cultures with L-Phe $(1 \mathrm{~g} / \mathrm{L})$ and recorded the generation of $268 \mathrm{mg} / \mathrm{L}$ of 2-PEA. This amount is very similar to the one reported in yeast ITD 00211, highlighting that the production by the strains of this study has not gone through the process of optimization.

\section{Conclusions}

This study presents preliminary evidence of differences between non-Saccharomyces yeasts found during fermentation of A. durangensis for the production of mescal. Particularly, Kluyveromyces yeasts have a high variability among them with respect to the production of volatile organic compounds, where it was evidenced that these have the extraordinary potential to produce aromas, particularly, 2 PE and 2 PEA.

Funding This work was supported by the Tecnologico Nacional de México [grant number 4551.12-P] and the Consejo Nacional de Ciencia y Tecnología (CONACyT) scholarship awarded to Pablo Jaciel AdameSoto 435680

\section{Compliance with ethical standards}

Conflict of interest The authors declare that they have no conflict of interest.

Research involving human participants and/or animal This article does not contain any studies with human or animal.

Informed consent Not applicable.

\section{References}

Beckner Whitener ME, Carlin S, Jacobson D et al (2015) Early fermentation volatile metabolite profile of non-Saccharomyces yeasts in red and white grape must: a targeted approach. LWT- Food Sci Technol 64:412-422. https://doi.org/10.1016/j.lwt.2015.05.018

Belloch C, Barrio E, Uruburu F et al (1997) Characterisation of four species of the genus Kluyveromyces by mitochondrial DNA restriction analysis. Syst Appl Microbiol 20:397-408. https://doi.org/10. 1016/S0723-2020(97)80008-2

Belloch C, Fernández-Espinar T, Querol A et al (2002) An analysis of inter- and intraspecific genetic variabilities in the Kluyveromyces marxianus group of yeast species for the reconsideration of the $\mathrm{K}$. lactis taxon. Yeast 19:257-268. https://doi.org/10.1002/yea.832

Calvo-Gómez O, Morales-López J, López MG (2004) Solid-phase microextraction-gas chromatographic-mass spectrometric analysis of garlic oil obtained by hydrodistillation. J Chromatogr A 1036: 91-93. https://doi.org/10.1016/j.chroma.2004.02.072

Celińska E, Kubiak P, Białas W et al (2013) Yarrowia lipolytica: the novel and promising 2-phenylethanol producer. J Ind Microbiol
Biotechnol 40:389-392. https://doi.org/10.1007/s10295-013-1240-

Chang JJ, Ho CY, Huang CC, et al. (2014) Flavor compound-producing yeast strains. US Patent No. 8703474 B2

Chreptowicz K, Wielechowska M, Główczyk-Zubek J, Rybak E, Mierzejewska J (2016) Production of natural 2-phenylethanol: from biotransformation to purified product. Food Bioprod Process 100: 275-281. https://doi.org/10.1016/j.fbp.2016.07.011

Chreptowicz K, Sternicka MK, Kowalska PD, Mierzejewska J (2018) Screening of yeasts for the production of 2-phenylethanol (rose aroma) in organic waste-based media. Lett Appl Microbiol 66:153-160

Ciani M, Morales P, Comitini F et al (2016) Non-conventional yeast species for lowering ethanol content of wines. Front Microbiol 7: 1-13. https://doi.org/10.3389/fmicb.2016.00642

Cordente AG, Curtin CD, Varela C, Pretorius IS (2012) Flavour-active wine yeasts. Appl Microbiol Biotechnol 96:601-618. https://doi. org/10.1007/s00253-012-4370-z

De León Rodríguez A, Escalante Minakata MDP, Jiménez García MI, Ordoñez Acevedo LG, Flores Flores JL, Barba de la Rosa AP (2008) Characterization of volatile compounds from ethnic Agave alcoholic beverages by gas chromatography-mass spectrometry. Food Technol Biotechnol 46:448-455

de Lima LA, Diniz RHS, de Queiroz MV, Fietto LG, Silveira WB (2018) Screening of yeasts isolated from Brazilian environments for the 2phenylethanol (2-PE) production. Biotechnol Bioprocess Eng 23: 326-332. https://doi.org/10.1007/s12257-018-0119-6

De los Rios-Deras GC, Rutiaga-Quiñones OM, López-Miranda J, PáezLerma J, López MG, Soto-Cruz NO (2015) Improving Agave durangensis must for enhanced fermentation. Effects on mezcal composition and sensory properties. Rev Mex Ing Quím 14:363$371 \mathrm{http}: / /$ www.redalyc.org/articulo.oa?id=62041194013

Díaz-Montaño DM, Délia ML, Estarrón-Espinosa M, Strehaiano P (2008) Fermentative capability and aroma compound production by yeast strains isolated from Agave tequilana Weber juice. Enzym Microb Technol 42:608-616. https://doi.org/10.1016/j.enzmictec. 2007.12.007

Escalante-Minakata P, Blaschek HP, Barba De La Rosa AP et al (2008) Identification of yeast and bacteria involved in the mezcal fermentation of Agave salmiana. Lett Appl Microbiol 46:626-630. https:// doi.org/10.1111/j.1472-765X.2008.02359.x

Eshkol N, Sendovski M, Bahalul M et al (2009) Production of 2phenylethanol from L-phenylalanine by a stress tolerant Saccharomyces cerevisiae strain. J Appl Microbiol 106:534-542. https://doi.org/10.1111/j.1365-2672.2008.04023.x

Etschmann MMW, Schrader J (2006) An aqueous-organic two-phase bioprocess for efficient production of the natural aroma chemicals 2-phenylethanol and 2-phenylethylacetate with yeast. Appl Microbiol Biotechnol 71:440-443. https://doi.org/10.1007/s00253005-0281-6

Etschmann MMW, Sell D, Schrader J (2003) Screening of yeasts for the production of the aroma compound 2-phenylethanol in a molassesbased medium. Biotechnol Lett 25:531-536. https://doi.org/10. 1023/A:1022890119847

Etschmann MMW, Sell D, Schrader J (2004) Medium optimization for the production of the aroma compound 2-phenylethanol using a genetic algorithm. J Mol Cat B: Enzymatic 29:187-193. https:// doi.org/10.1016/j.molcatb.2003.10.014

Etschmann MMW, Sell D, Schrader J (2005) Production of 2phenylethanol and 2-phenylethylacetate from L-phenylalanine by coupling whole-cell biocatalysis with organophilic pervaporation. Biotechnol Bioeng 92:624-634

Fabre CE, Blanc PJ, Goma G (1998) Production of 2-phenylethyl alcohol by Kluyveromyces marxianus. Biotechnol Prog 14:270-274. https:// doi.org/10.1021/bp9701022 
Garavaglia J, Flôres SH, Pizzolato TM et al (2007) Bioconversion of Lphenylalanine into 2-phenylethanol by Kluyveromyces marxianus in grape must cultures. World J Microb Biotechnol 23:1273-1279

Gethins L, Guneser O, Demirkol A et al (2015) Influence of carbon and nitrogen source on production of volatile fragrance and flavour metabolites by the yeast Kluyveromyces marxianus. Yeast 32:67-76. https://doi.org/10.1002/yea.3047

González B, Vázquez J, Morcillo-Parra MÁ et al (2018) The production of aromatic alcohols in non- Saccharomyces wine yeast is modulated by nutrient availability. Food Microbiol 74:64-74. https://doi.org/ 10.1016/j.fm.2018.03.003

Guo D, Zhang L, Pan H, Li X (2017) Metabolic engineering of Escherichia coli for production of 2-phenylethylacetate from L-phenylalanine. Microbiology Open 6:1-5. https://doi.org/10.1002/ mbo3.486

Hazelwood LH, Daran J-MG, van Maris AJA et al (2008) The Ehrlich pathway for fusel alcohol production: a century of research on Saccharomyces cerevisiae metabolism. Appl Environ Microbiol 74:2259-2266. https://doi.org/10.1128/AEM.02625-07

Hernández-Carbajal G, Rutiaga-Quiñones OM, Pérez-Silva A et al (2013) Screening of native yeast from Agave duranguensis fermentation for isoamyl acetate production. Brazilian Arch Biol Technol 56:357-363. https://doi.org/10.1590/S1516-89132013000300002

Jolly NP, Varela C, Pretorius IS (2014) Not your ordinary yeast: nonSaccharomyces yeasts in wine production uncovered. FEMS Yeast Res 14:215-237. https://doi.org/10.1111/1567-1364.12111

Kirchmayr MR, Segura-García LE, Lappe-Oliveras P et al (2017) Impact of environmental conditions and process modifications on microbial diversity, fermentation efficiency and chemical profile during the fermentation of mezcal in Oaxaca. LWT - Food Sci Technol 79: 160-169. https://doi.org/10.1016/j.lwt.2016.12.052

Kurtzman CP, Fell JW, Boekhout T (2011) The yeasts: a taxonomic study. Elsevier, Amsterdam, The Netherlands

Lachance MA (1995) Yeast communities in a natural tequila fermentation. Antonie Van Leeuwenhoek 68:151-160. https://doi.org/10. 1007/BF00873100

Lane MM, Morrissey JP (2010) Kluyveromyces marxianus: a yeast emerging from its sister's shadow. Fungal Biol Rev 24:17-26. https://doi.org/10.1016/j.fbr.2010.01.001

Lappe P, Ulloa M, Arce-Arocha G, Caceres-Farfan M, Tapia-Tussell R, Pérez-Brito D, Larque A (2004) Isolation and identification of the mycobiota present in Agave fourcroydes. Eleventh International Congress of Yeast, Book of Abstracts

Lappe-Oliveras P, Moreno-Terrazas R, Arrizón-Gaviño J, Herrera-Suárez T, García-Mendoza A, Gschaedler-Mathis A (2008) Yeasts associated with the production of Mexican alcoholic nondistilled and distilled Agave beverages. FEMS Yeast Res. https://doi.org/10.1111/j. 1567-1364.2008.00430.x

Liu SQ, Holland R, Crow VL (2004) Esters and their biosynthesis in fermented dairy products: a review. Int Dairy J 14:923-945

Loser C, Urit T, Bley T (2014) Perspectives for the biotechnological production of ethyl acetate by yeasts. Appl Microbiol Biotechnol 98:5397-5415

Lu X, Wang Y, Zong H, Ji H, Zhuge B, Dong Z (2016) Bioconversion of L-phenylalanine to 2-phenylethanol by the novel stress-tolerant yeast Candida glycerinogenes WL2002-5. Bioeng 5979:1-6

Martell Nevárez MA, Córdova Gurrola EE, López Miranda J et al (2011) Effect of fermentation temperature on chemical composition of mescals made from Agave duranguensis juice with different native yeast genera. African J Microbiol Res 5:3669-3676. https://doi.org/10. 5897/AJMR11.467

Martínez O, Sánchez A, Font X, Barrena R (2018) Bioproduction of 2phenylethanol and 2-phenethyl acetate by Kluyveromyces marxianus through the solid-state fermentation of sugarcane bagasse. Microbiol Biotechnol Appl. https://doi.org/10.1007/s00253018-8964-y
Masneuf-Pomarede I, Bely M, Marullo P, Albertin W (2016) The genetics of non-conventional wine yeasts: current knowledge and future challenges. Front Microbiol 6. https://doi.org/10.3389/fmicb.2015. 01563

Mei J, Min H, Lu Z (2009) Enhanced biotransformation of Lphenylalanine to 2-phenylethanol using an in situ product adsorption technique. Process Biochem 44:886-890. https://doi.org/10.1016/j. procbio.2009.04.012

Moreira N, Mendes F, Hogg T, Vasconcelos I (2005) Alcohols, esters and heavy Sulphur compounds production by pure and mixed cultures of apiculate wine yeasts. Int J Food Microbiol 103:285-294. https:// doi.org/10.1016/j.jffoodmicro.2004.12.029

Morrissey JP, Etschmann MMW, Schrader J, De Billerbeck GM (2015) Cell factory applications of the yeast Kluyveromyces marxianus for the biotechnological production of natural flavour and fragrance molecules. Yeast 32:3-16. https://doi.org/10.1002/yea.3054

Narváez-Zapata JA, Rojas-Herrera RA, Rodríguez-Luna IC, LarraldeCorona CP (2010) Culture-independent analysis of lactic acid bacteria diversity associated with mezcal fermentation. Curr Microbiol 61:444-450. https://doi.org/10.1007/s00284-010-9636-z

Nuñez-Guerrero ME, Páez-Lerma JB, Rutiaga-Quiñones OM et al (2016) Performance of mixtures of Saccharomyces and nonSaccharomyces native yeasts during alcoholic fermentation of Agave duranguensis juice. Food Microbiol 54:91-97. https://doi. org/10.1016/j.fm.2015.10.011

Ortiz-Merino RA, Varela JA, Coughlan AY, Hoshida H, da Silveira WB, Wilde C, Kuijpers NGA, Geertman JM, Wolfe KH, Morrissey JP (2018) Ploidy variation in Kluyveromyces marxianus separates dairy and non-dairy isolates. Front Genet 9:0-16. https://doi.org/10.3389/ fgene.2018.00094

Padilla B, García-Fernández D, González B et al (2016) Yeast biodiversity from DOQ Priorat Uninoculated fermentations. Front Microbiol 7:930

Páez-Lerma JB, Rutiaga-Quiñones OM, Aguilar-González C et al (2010) Agave duranguensis predominant microorganisms along alcoholic fermentation of Agave duranguensis. Agrofaz 10:167-173

Páez-Lerma JB, Arias-García A, Rutiaga-Quiñones OM et al (2013) Yeasts isolated from the alcoholic fermentation of Agave duranguensis during mezcal production. Food Biotechnol 27:342356. https://doi.org/10.1080/08905436.2013.840788

Pérez-Brito D, Magaña-Alvarez A, Lappe-Oliveras P et al (2015) Genetic diversity of Clavispora lusitaniae isolated from Agave fourcroydes Lem, as revealed by DNA fingerprinting. J Microbiol 53:14-20. https://doi.org/10.1007/s12275-015-4373-4

Pires EJ, Teixeira JA, Brányik T, Vicente AA (2014) Yeast: the soul of beer's aroma - a review of flavour-active esters and higher alcohols produced by the brewing yeast. Appl Microbiol Biotechnol 98: 1937-1949. https://doi.org/10.1007/s00253-013-5470-0

Rodrigues de Miranda L (1979) Clavispora, a new yeast genus of the Saccharomycetales. Antonie Van Leeuwenhoek 45:479-483. https://doi.org/10.1007/BF00443285

Rodríguez-Sifuentes L, Páez-Lerma JB, Rutiaga-Quiñones OM et al (2014) Identification of a yeast strain as a potential stuck wine fermentation restarter: a kinetic characterization. CYTA - J Food 12:18. https://doi.org/10.1080/19476337.2013.776637

Rojas V, Gil JV, Piaga F, Manzanares P (2001) Studies on acetate ester production by non-Saccharomyces wine yeasts. Int J Food Microbiol 70:283-289

Rutiaga-Quiñones OM, Córdova É, Martell-Nevárez MA et al (2012) Volatile compound production in Agave duranguensis juice fermentations using four native yeasts and $\mathrm{NH} 4 \mathrm{Cl}$ supplementation. Eur Food Res Technol 235:29-35. https://doi.org/10.1007/s00217-0121729-4

Sambrook J, Russell RW (2001) Molecular cloning: a laboratory manual, 3rd edn. Cold spring harbor, New York 
Schrader J, Etschmann MM, Sell D et al (2004) Applied biocatalysis for the synthesis of natural flavour compounds-current industrial processes and future prospects. Biotechnol Lett 26:463-472. https://doi. org/10.1023/B:BILE.0000019576.80594.0e

Styger G, Prior B, Bauer FF (2011) Wine flavor and aroma. Microbiol Biotechnol 38:1145-1159. https://doi.org/10.1007/s10295-0111018-4

Sukhotina NN, Naumova ES, Naumov GI (2006) Molecular polymorphism of the yeast Kluyveromyces dobzhanskii: geographic populations. Dokl Biochem Biophys 409:236-240. https://doi.org/10. 1134/S1607672906040120

Verdugo-Valdez A, Segura-Garcia L, Kirchmayr M, Ramírez-Rodríguez P, González-Esquinca A, Coria R, Gschaedler-Mathis A (2011) Yeast communities associated with artisanal mezcal fermentations from Agave salmiana. Anton Leeuw Int J Gen Mol Microbiol 100: 497-506. https://doi.org/10.1007/s10482-011-9605-y
Viana F, Belloch C, Vallés S, Manzanares P (2011) Monitoring a mixed starter of Hanseniaspora vineae-Saccharomyces cerevisiae in natural must: impact on 2-phenylethyl acetate production. Int J Food Microbiol 151:235-240

White TJ, Bruns TD, Lee SB, Taylor JW (1990) Amplification and direct sequencing of fungal ribosomal RNA genes for phylogenetics. Academic Press, Cambridge, pp 315-322

Yin S, Zhou H, Xiao X, Lang T, Liang J, Wang C (2015) Improving 2phenylethanol production via Ehrlich pathway using genetic engineered Saccharomyces cerevisiae strains. Curr Microbiol 70: 762-767. https://doi.org/10.1007/s00284-015-0785-y

Publisher's note Springer Nature remains neutral with regard to jurisdictional claims in published maps and institutional affiliations. 